\title{
Preliminary Report of Microcephaly Potentially Associated with Zika Virus Infection During Pregnancy — Colombia, January-November 2016
}

\author{
Esther Liliana Cuevas, MS, MPH${ }^{1}$; Van T. Tong, $\mathrm{MPH}^{2}$; Nathaly Rozo ${ }^{1}$; Diana Valencia, $\mathrm{MS}^{2}$; Oscar Pacheco, MD ${ }^{1}$; Suzanne M. Gilboa, PhD ${ }^{2}$; \\ Marcela Mercado, MS ${ }^{1}$; Christina M. Renquist, MPH ${ }^{2}$; Maritza González, MD ${ }^{1}$; Elizabeth C. Ailes, PhD ${ }^{2}$; Carolina Duarte ${ }^{1}$; Valerie Godoshian, MPH ${ }^{2}$; \\ Christina L. Sancken, $\mathrm{MPH}^{2}$; Angelica Maria Rico Turca ${ }^{1}$; Dinorah L. Calles, PhD²; Martha Ayala ${ }^{1}$; Paula Morgan, MPH²; Erika Natalia Tolosa \\ Perez, MD ${ }^{1}$; Hernan Quijada Bonilla ${ }^{1}$; Ruben Caceres Gomez ${ }^{1}$; Ana Carolina Estupiñan ${ }^{3}$; Maria Luz Gunturiz ${ }^{1}$; Dana Meaney-Delman, MD²; \\ Denise J. Jamieson, $\mathrm{MD}^{2}$; Margaret A. Honein, $\mathrm{PhD}^{2}$; Martha Lucia Ospina Martínez, MD ${ }^{1}$
}

On December 9, 2016, this report was posted as an MMWR Early Release on the MMWR website (http://www.cdc.gov/mmwr).

In Colombia, approximately 105,000 suspected cases of Zika virus disease (diagnosed based on clinical symptoms, regardless of laboratory confirmation) were reported during August 9, 2015-November 12, 2016, including nearly 20,000 in pregnant women $(1,2)$. Zika virus infection during pregnancy is a known cause of microcephaly and serious congenital brain abnormalities and has been associated with other birth defects related to central nervous system damage (3). Colombia's Instituto Nacional de Salud (INS) maintains national surveillance for birth defects, including microcephaly and other central nervous system defects. This report provides preliminary information on cases of congenital microcephaly identified in Colombia during epidemiologic weeks 5-45 (January 31-November 12) in 2016. During this period, 476 cases of microcephaly were reported, compared with 110 cases reported during the same period in 2015. The temporal association between reported Zika virus infections and the occurrence of microcephaly, with the peak number of reported microcephaly cases occurring approximately 24 weeks after the peak of the Zika virus disease outbreak, provides evidence suggesting that the period of highest risk is during the first trimester of pregnancy and early in the second trimester of pregnancy. Microcephaly prevalence increased more than fourfold overall during the study period, from 2.1 per 10,000 live births in 2015 to 9.6 in 2016. Ongoing population-based birth defects surveillance is essential for monitoring the impact of Zika virus infection during pregnancy on birth defects prevalence and measuring the success in preventing Zika virus infection and its consequences, including microcephaly.

INS maintains ongoing passive, national surveillance in Colombia for both symptomatic Zika virus disease and major birth defects. Surveillance for Zika virus disease based on clinical symptoms and laboratory testing started in August 2015 in Colombia, and following a cluster of laboratory-confirmed cases of Zika virus disease, immediate mandatory reporting began in October 2015. At the time, symptomatic Zika virus disease was defined as illness with fever and at least one additional symptom (rash, nonpurulent conjunctivitis, headache, pruritus, arthralgia, myalgia, or malaise) of unknown etiology. Beginning December 24, 2015, the case definition has included both fever and rash, and at least one of the other symptoms. Colombia's birth defects surveillance system includes reporting of microcephaly (International Classification of Disease, 10th Revision code Q02) among live births and pregnancy losses (including spontaneous abortions, pregnancy terminations, and stillbirths) from all reporting areas.* Congenital microcephaly in a newborn is defined as having a head circumference below the third percentile for gestational age and sex. The following clinical specimens are requested for all infants and fetuses with microcephaly to ascertain whether the mother was infected with Zika virus during pregnancy: maternal serum, infant serum from cord and peripheral blood specimens, cerebrospinal fluid (if obtained from infant for clinical reasons), and tissues from fetal losses. Specimens are tested for Zika virus RNA by real-time reverse transcription-polymerase chain reaction (rRT-PCR), for serologic evidence of infection by Zika immunoglobulin M (IgM) antibody capture enzyme-linked immunosorbent assay (MAC-ELISA), or for Zika viral antigens by immunohistochemistry, as well as for the presence of other infections (syphilis, toxoplasmosis, rubella, cytomegalovirus, herpes simplex, and other agents); high resolution karyotyping is also performed. The Colombian Ministry of Health recommends a diagnostic algorithm for testing of specimens from all products of conception and infants whose mothers had Zika virus infection during pregnancy; however, these specimens are not always collected soon after birth or submitted for Zika virus testing. Recommended neuroimaging includes cranial ultrasound for all infants, and if abnormalities are observed on cranial ultrasound then computed tomography scan or magnetic resonance imaging might be necessary. Microcephaly prevalence per 10,000 live births was calculated overall, by reporting area, and by month of pregnancy completion for epidemiologic weeks 5-45 in 2016. A prevalence ratio (PR) was calculated by dividing the prevalence in 2016 by the prevalence in 2015, and 95\% confidence intervals (CIs) for the PR were calculated using Poisson regression.

\footnotetext{
${ }^{*}$ http://www.ins.gov.co/lineas-de-accion/Subdireccion-Vigilancia/sivigila/ Protocolos\%20SIVIGILA/PRO\%20Microcefalia.pdf.
} 
The outbreak of Zika virus disease among pregnant women in Colombia peaked during epidemiologic week 4 in 2016. Reported cases of microcephaly peaked during epidemiologic week 28 in 2016 (24 weeks after the peak of reported cases of Zika virus disease) (Figure 1). During epidemiologic weeks 5-45 in 2016, a total of 476 infants with microcephaly were reported in Colombia; 28 (85\%) of the 33 reporting areas in Colombia reported at least one case of microcephaly (supplemental table https://stacks.cdc.gov/view/cdc/42918). Overall, the prevalence of reported microcephaly was approximately 9.6 per 10,000 live births. Among areas reporting at least one case of microcephaly, the prevalence ranged from two per 10,000 live births (Nariño and Quindío) to 29 (Amazonas) (Figure 2). Microcephaly cases were reported in areas that include locations $>2000$ meters $(6,562$ feet) above sea level (e.g., Bogotá) without active Zika virus transmission; these cases, if Zika-related, likely resulted from travel-associated or sexually transmitted Zika virus infections.

The prevalence of microcephaly increased more than fourfold during epidemiologic weeks 5-45 in 2016 compared with the same period in 2015 ( $\mathrm{PR}=4.5)$ (Table). Peak prevalence of microcephaly was registered in July 2016, when the prevalence was ninefold higher than in July 2015 (PR = 9.0). In 2016, among all microcephaly cases, 432 (91\%) occurred in live born infants, and 44 (9\%) occurred among pregnancy losses; in 2015, among 110 reported cases of microcephaly, 90 (82\%) occurred in live born infants, and 20 (18\%) occurred among pregnancy losses.

FIGURE 1. Date of symptom onset of reported cases of Zika virus disease among pregnant women* and date of birth of infants or of pregnancy loss for fetuses with reported microcephaly ${ }^{\dagger}$ _ Colombia, August 9, 2015 (epidemiologic week 32)-November 12, 2016 (week 45)

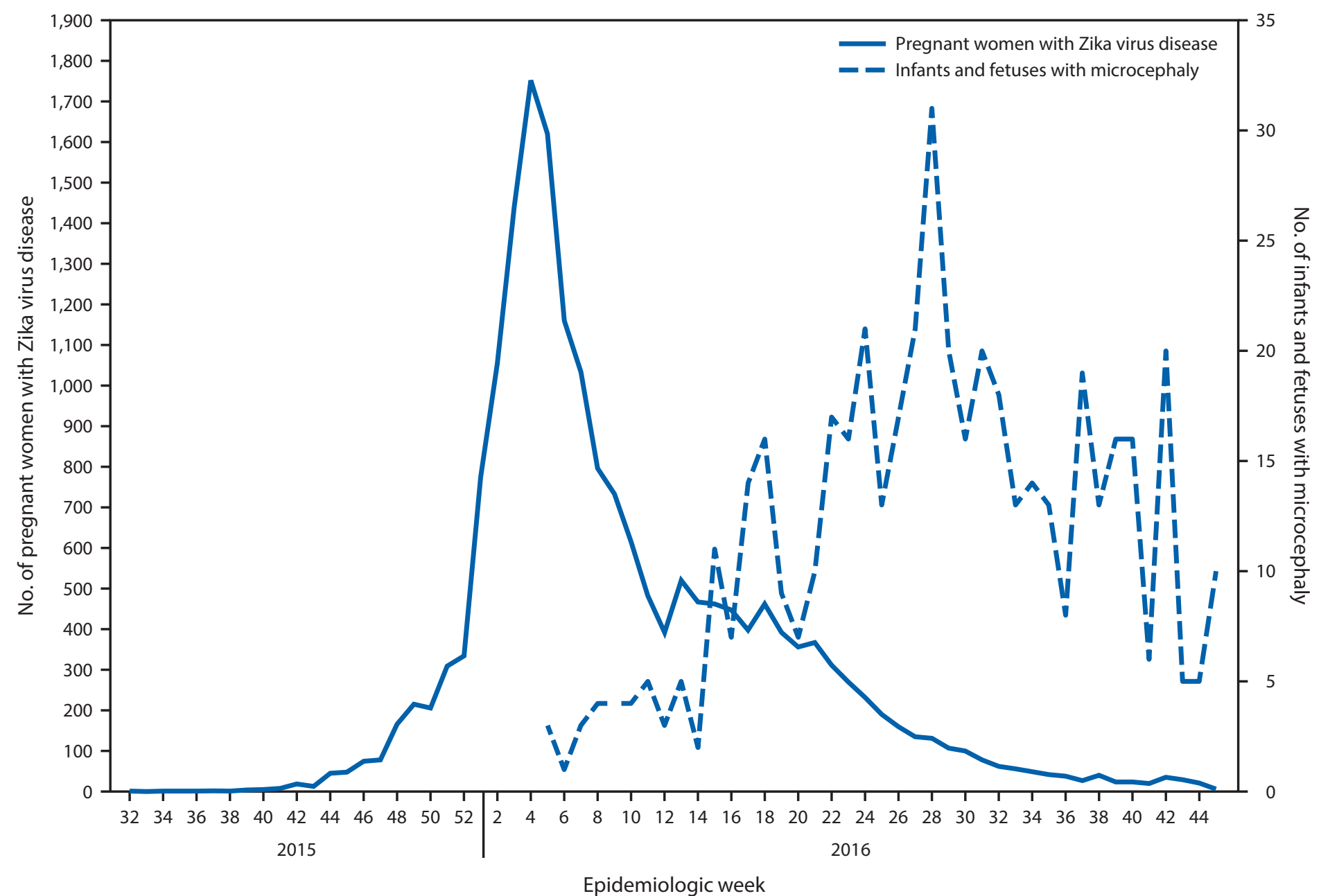

\footnotetext{
* Pregnant women with Zika virus disease include women with symptoms of Zika virus disease, regardless of laboratory confirmation; epidemiologic week was based on date of symptom onset. Immediate mandatory reporting of clinical symptoms of Zika virus disease with laboratory testing began in Colombia in October 2015. During October-December 23, 2015, symptomatic Zika virus disease was defined as fever and at least one additional symptom (rash, nonpurulent conjunctivitis, headache, pruritus, arthralgia, myalgia, or malaise). Beginning December 24, 2015, it was defined as fever and rash with at least one of the other symptoms.

+ Congenital microcephaly in a newborn is defined as head circumference less than the third percentile, compared with the normal standard adjusted for gestational age and sex; epidemiologic week was based on the date of birth or pregnancy loss.
} 
FIGURE 2. Prevalence of congenital microcephaly per 10,000 live births during epidemiologic weeks 5-45 (January 31-November 12), by reporting area - Colombia, 2016

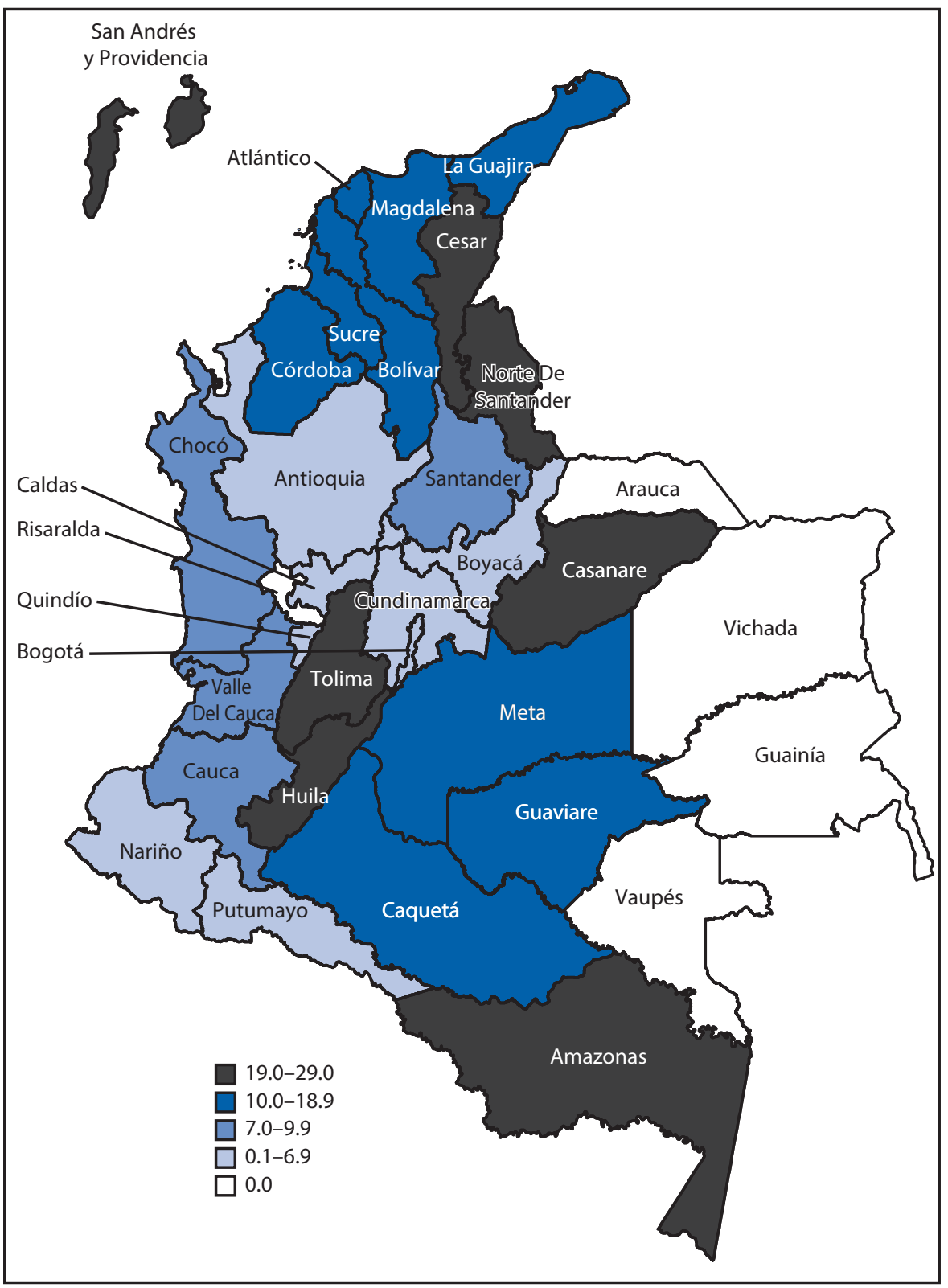

Among the 476 infants and fetuses with microcephaly reported during epidemiologic weeks $5-45$ in 2016, a total of 306 (64\%) were tested for Zika virus infection; 147 (48\%) had laboratory evidence of Zika virus infection by RT-PCR or immunohistochemistry on any placental, fetal, or infant specimen, and five of six tested had serologic evidence of infection by MAC-ELISA. Among 121 infants tested for other pathogens, $26(21 \%)$ had evidence of infection with other pathogens, including toxoplasmosis (15 infants), herpes simplex (six), cytomegalovirus (four) and syphilis (one); among these 26 infants, $17(65 \%)$ had evidence of coinfection with Zika virus (14 of 15 with toxoplasmosis, two of six with herpes, and one of four with cytomegalovirus). Neuroimaging results were available for $32 \%$ of all microcephaly cases. Among 476 infants or fetuses with microcephaly, mothers of 164 (34\%) reported having symptoms compatible with Zika virus infection during pregnancy.

\section{Discussion}

Based on an average full term gestation, the 24-week period from the peak of the Zika virus outbreak to the peak in reported microcephaly occurrence suggests that the greatest risk for microcephaly is associated with Zika virus infection during the first trimester and early in the second trimester of pregnancy. During epidemiologic weeks 5-45, there was more than a fourfold increase in reported microcephaly cases in Colombia in 2016, compared with the previous year. Although the microcephaly prevalence in 2016 among infants likely exposed to Zika virus in utero (9.6 per 10,000 live births) in Colombia was not much higher than the median of microcephaly prevalence (6.6 per 10,000 live births) reported by passive surveillance in 17 U.S. states during 2009-2013 (4), the comparison with 2015 Colombia data indicates the magnitude of the increase.

The Zika virus disease outbreak in the World Health Organization's Region of the Americas began in Brazil, which first reported a laboratory-confirmed Zika virus outbreak in May 2015; Colombia confirmed local transmission of Zika virus about 5 months later, in October $2015 .^{\dagger}$ In 2015, microcephaly prevalence in Brazil was 5.5 per 10,000 live births, representing an approximate ninefold increase over the average prevalence during the previous 14 years $(5,6)$. In Colombia, the relative increase has been smaller (fourfold); however, the baseline microcephaly prevalence was 2.1 per 10,000 live births in 2015, at least three times higher than Brazil's reported baseline. There are several possible reasons for differences between the reported baseline microcephaly prevalences in Brazil and Colombia, as well as the differences in increases of microcephaly in the context of the Zika virus outbreaks in the two countries. First, 50\%-75\% of the population of Colombia reside at altitudes above 2,000

\footnotetext{
$\dagger^{\dagger}$ http://www.paho.org/hq/index.php?option=com_docman\&task=doc_view\& Itemid=270\&gid=36428\&lang=en.
} 
Morbidity and Mortality Weekly Report

TABLE. Reported cases of congenital microcephaly* during epidemiologic weeks 5-45 (January 31-November 12) — Colombia, 2015 and 2016

\begin{tabular}{|c|c|c|c|c|c|c|c|}
\hline \multirow[b]{2}{*}{ Month pregnancy ended } & \multicolumn{2}{|c|}{$\begin{array}{l}\text { No. of microcephaly cases } \\
\text { reported }\end{array}$} & \multicolumn{2}{|c|}{ No. of live births } & \multicolumn{2}{|c|}{$\begin{array}{l}\text { Prevalence of microcephaly per } \\
10,000 \text { live births }\end{array}$} & \multirow{2}{*}{$\begin{array}{c}\text { Prevalence } \\
\text { ratio, comparing } \\
2016 \text { to } 2015,(95 \% \mathrm{Cl})\end{array}$} \\
\hline & 2015 & 2016 & 2015 & 2016 & 2015 & 2016 & \\
\hline February & 4 & 12 & 48,384 & 50,367 & 0.8 & 2.4 & $2.9(0.9-8.9)$ \\
\hline March & 16 & 18 & 55,102 & 54,348 & 2.9 & 3.3 & $1.1(0.6-2.2)$ \\
\hline April & 16 & 36 & 52,535 & 52,612 & 3.0 & 6.8 & $2.2(1.2-4.0)$ \\
\hline May & 12 & 47 & 54,642 & 53,464 & 2.2 & 8.8 & $4.0(2.1-7.5)$ \\
\hline June & 11 & 75 & 53,929 & 51,748 & 2.0 & 14.5 & $7.1(3.8-13.4)$ \\
\hline July & 11 & 94 & 56,160 & 53,046 & 2.0 & 17.7 & $9.0(4.8-16.9)$ \\
\hline August & 15 & 71 & 55,290 & 55,709 & 2.7 & 12.7 & $4.7(2.7-8.2)$ \\
\hline September & 10 & 60 & 58,835 & 56,539 & 1.7 & 10.6 & $6.2(3.2-12.2)$ \\
\hline October $^{\dagger}$ & 11 & 49 & 56,870 & 49,262 & 1.9 & 9.9 & $5.1(2.7-9.9)$ \\
\hline November ${ }^{\S}$ & 4 & 14 & 24,317 & 21,193 & 1.6 & 6.6 & $4.0(1.3-12.2)$ \\
\hline Total & 110 & 476 & 516,064 & 498,288 & 2.1 & 9.6 & $4.5(3.6-5.5)$ \\
\hline
\end{tabular}

Abbreviation: $\mathrm{Cl}=$ confidence interval.

* Congenital microcephaly in a newborn is defined as head circumference less than the third percentile, compared with the normal standard adjusted for gestational age and sex. Table includes pregnancies ending during this period, regardless of Zika virus testing or pregnancy outcome (i.e., live births and pregnancy losses [spontaneous abortions, pregnancy terminations, and stillbirths combined]).

† October 2016 birth data are preliminary.

$\S$ Number of cases of microcephaly and number of live births are for the period November 1-12 in both 2015 and 2016. November 1-12, 2016, birth data are preliminary.

meters, in areas without active, vectorborne Zika virus transmission (7). Second, microcephaly is a difficult birth defect to monitor because there are inconsistent definitions, obtaining accurate measurements is challenging, and terminology is inconsistent. Because of these challenges, prevalence estimates vary widely among countries and among surveillance systems within the United States (4). Third, the reports of microcephaly from Brazil might have served as an early warning. As evidence was emerging about the link between Zika virus infection and microcephaly, the Colombian Ministry of Health issued a recommendation in February 2016 advising women to consider delaying pregnancy for 6 months, which might have affected subsequent birth rates. ${ }^{\$}$ The number of live births in Colombia during epidemiologic weeks $5-45$ decreased by approximately 18,000 from 2015 to 2016.

The findings in this report are subject to at least four limitations. First, the report includes all cases of microcephaly and not just those linked to Zika virus. The majority of cases of microcephaly lacked laboratory confirmation of Zika virus infection. Possible explanations are that specimens were not submitted for all cases, specimens that were submitted were not collected within the recommended time frames (maternal serum specimens within 5 days of date of symptom onset for rRT-PCR testing and infant serum or fetal tissue specimens within 2 days of delivery), and neuroimaging studies were not available for the majority of patients (68\%). Second, ascertainment of birth defects, including microcephaly, tends to be more complete among live born infants than among pregnancy losses, because of the condition of the fetus at the time of the loss as well as the relatively infrequent use of fetal autopsy to

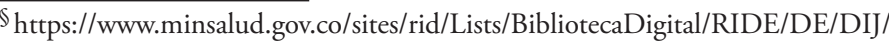
circular-0013-2016.pdf.
}

determine the cause of fetal death, leading to underestimation of the number of cases of microcephaly, especially among pregnancy losses (8). In addition, because microcephaly is a rare outcome, prevalence ratios comparing 2016 and 2015 might be unstable and should be interpreted with caution. Third, passive reporting systems tend to have less complete ascertainment of all birth defects compared with active surveillance systems (9). Finally, the ascertainment of birth defects generally does not capture infants or fetuses whose birth defects are not apparent prenatally or at delivery, but rather are identified several months after birth. Certain critical outcomes, such as deceleration of brain growth among infants who are born with normal head circumferences, are not captured by this surveillance (10).

Colombia's national population-based surveillance system for birth defects is based on passive reporting, which provides critical data for monitoring the impact of teratogens and describing trends but likely underestimates the actual prevalence of birth defects, including those defects associated with Zika virus infection during pregnancy. Also, Colombia's Zika virus surveillance is based on clinical symptoms, and asymptomatic Zika virus infections are not monitored by surveillance. Therefore, the overall percentage of women who are infected with Zika virus, or infected in early pregnancy or during the periconceptional period is unknown. To better understand the effects of Zika virus, INS and CDC are collaborating on "Proyecto Vigilancia de Embarazadas con Zika" (Enhanced Surveillance Project of Pregnant Women with Zika) to conduct intensified active monitoring in three cities in Colombia with high incidence of Zika virus disease in pregnant women. This project, which includes systematic collection of laboratory specimens for Zika virus testing, will provide more accurate estimates of the risk for microcephaly 


\section{Summary}

What is already known about this topic?

Zika virus infection during pregnancy can cause microcephaly and serious brain abnormalities in fetuses and infants exposed in utero. The Zika virus disease outbreak in the World Health Organization's Region of the Americas began in Brazil, which first reported a laboratory-confirmed Zika virus outbreak in May 2015; Colombia confirmed local transmission of Zika virus about 5 months later, in October 2015. Colombia's Instituto Nacional de Salud maintains national surveillance for birth defects, including microcephaly.

What is added by this report?

This report provides preliminary national birth defects surveillance data on congenital microcephaly following a large outbreak of Zika virus infection in Colombia. Microcephaly prevalence increased more than fourfold overall in 2016 compared with 2015, with a ninefold increase in July 2016 (the peak month) compared with July 2015. The temporal association between Zika virus infections and microcephaly, with the peak of reported microcephaly occurring approximately 24 weeks after the peak of the Zika outbreak, provides evidence that the greatest risk period is likely the first trimester of pregnancy and early in the second trimester of pregnancy.

What are the implications for public health practice?

Colombia has experienced a significant increase in congenital microcephaly in 2016 following the peak of the Zika virus disease outbreak. Ongoing population-based birth defects surveillance is essential for monitoring the impact of Zika virus infection during pregnancy on birth defects prevalence and measuring the success in preventing Zika virus infection and its consequences, including microcephaly.

and other adverse birth outcomes among fetuses and infants of mothers with Zika virus disease during pregnancy.

In the absence of a vaccine to prevent $Z$ ika virus infection or a specific medication for treatment, prevention strategies include avoiding travel to areas with active Zika virus transmission, preventing mosquito bites through personal protection and vector control, and avoiding sexual transmission. Ongoing population-based birth defects surveillance provides critical data for monitoring the impact of teratogens, including Zika virus infection, and will be an essential tool to evaluate success in preventing microcephaly and congenital Zika syndrome.

\section{Acknowledgments}

Claudia Marcela Castro; Lina María Erazo Marquez; Esther Cristina Barros; Pablo Chaparro; Nubia Narváez; Greace Alejandra Avila Mellizo, María Eugenia Pinilla; Andrea Rodríguez Jiménez; Alexandra Caicedo; Luis Roa; Jorge Luis Díaz Moreno; Flavio
Enrique Garzón Romero A; Javier Madero Reales; Eliana Barón Velasco; Karen Reyes Hernández; Luz Mary Velandia Nieto: Diana Marcela Walteros Acero; Ana Victoria Padilla; Alfonso Campo Carey; Ana Maria Blandon; Angelica Rojas Barcena; Diana Parra; Irene Alejandra; Javier Madero; Natalia Gutierrez; Nidia Gonzalez; Norma Constanza Cuellar Espita; Paloma Sanchez; Paula Ramirez; Sandra Misnaza; Sandra Rivera; Victor Martinez Gomez; Yurani Sanchez Rodriguez; Wendy Luz Gomez, Yuli Andrea Gamboa; Amparo Sabogal; Andrea Cristancho; Camilo Alfonso; Catalina Arias; Claudia Marcela Munóz; German Ernesto Torres; Ivonie Alayon; Julio Cesar Martinez; Katherine Jiménez Gamarra; Lilian Rodriguez; Luis Carlos Gómez; Patricia Salas; Teodolinda Vega; Vilma Izquierdo; Adriana Gomez Rubio; Clara Maestre Matos, Instituto Nacional de Salud, Bogotá, Colombia; Secretaries of Health from each of the departments, districts, and municipalities in Colombia.

\footnotetext{
${ }^{1}$ Instituto Nacional de Salud, Bogotá, Colombia; ${ }^{2}$ National Center on Birth Defects and Developmental Disabilities, CDC; ${ }^{3}$ Ministerio de Salud y Protección Social, Bogotá, Colombia.

Corresponding author: Margaret A. Honein, zikamch@cdc.gov, 770-488-7100.
}

\section{References}

1. Instituto Nacional de Salud. Epidemiological week 45 Bogota, Colombia 2016. http://www.ins.gov.co/boletin-epidemiologico/Paginas/default.aspx

2. Pacheco O, Beltrán M, Nelson CA, et al. Zika virus disease in Colombia-preliminary report. N Engl J Med 2016. Epub June 15, 2016. http://dx.doi.org/10.1056/NEJMoa1604037

3. Rasmussen SA, Jamieson DJ, Honein MA, Petersen LR. Zika virus and birth defects - reviewing the evidence for causality. N Engl J Med 2016;374:1981-7. http://dx.doi.org/10.1056/NEJMsr1604338

4. Cragan JD, Isenburg JL, Parker SE, et al.; National Birth Defects Prevention Network. Population-based microcephaly surveillance in the United States, 2009 to 2013: an analysis of potential sources of variation. Birth Defects Res A Clin Mol Teratol 2016;106:972-82. http://dx.doi. org/10.1002/bdra.23587

5. Marinho F, Araújo VE, Porto DL, et al. Microcephaly in Brazil: prevalence and characterization of cases from the Information System on Live Births (Sinasc), 2000-2015. Epidemiol Serv Saude 2016;25:701-12.

6. Kleber de Oliveira W, Cortez-Escalante J, De Oliveira WT, et al. Increase in reported prevalence of microcephaly in infants born to women living in areas with confirmed Zika virus transmission during the first trimester of pregnancy-Brazil, 2015. MMWR Morb Mortal Wkly Rep 2016;65:242-7. http://dx.doi.org/10.15585/mmwr.mm6509e2

7. Departamento Administrativo Nacional de Estadística. Nacimientos por área de ocurrencia y sexo, según grupos de edad de la madre 2016. http://www.dane.gov.co/

8. Duke CW, Alverson CJ, Correa A. Fetal death certificates as a source of surveillance data for stillbirths with birth defects. Public Health Rep 2007;122:664-9.

9. Anderka M, Mai CT, Romitti PA, et al. Development and implementation of the first national data quality standards for population-based birth defects surveillance programs in the United States. BMC Public Health 2015;15:925. http://dx.doi.org/10.1186/s12889-015-2223-2

10. van der Linden V, Pessoa A, Dobyns W, et al. Description of 13 infants born during October 2015-January 2016 with congenital Zika virus infection without microcephaly at birth-Brazil. MMWR Morb Mortal Wkly Rep 2016;65:1343-8. http://dx.doi.org/10.15585/mmwr.mm6547e2 